\title{
Health services performance for TB treatment in Brazil: a cross-sectional study
}

Tereza CS Villa ${ }^{*}$, Antônio Ruffino-Netto ${ }^{2}$, Lucia M Scatena ${ }^{3}$, Rubia LP Andrade ${ }^{4}$, Maria EF Brunello ${ }^{4}$, Jordana A Nogueira ${ }^{5}$, Pedro F Palha ${ }^{4}$, Lenilde D Sá ${ }^{6}$, Marluce MA Assis ${ }^{7}$, Silvia HF Vendramini ${ }^{8}$, Aline A Monroe ${ }^{4}$, Ricardo A Arcêncio ${ }^{4}$ and Tiemi Arakawa ${ }^{4}$

\begin{abstract}
Background: Researches to evaluate Primary Health Care performance in TB control in Brazil show that different cities aggregate local specificities in the dynamics of coping with the disease. This study aims to evaluate health services' performance in TB treatment in cities across different Brazilian regions.

Methods: This cross-sectional study was conducted in five cities that are considered priorities for TB control in Brazil: Itaboraí (ITA), Ribeirão Preto (RP) and São José do Rio Preto (SJRP) in the Southeast; Campina Grande (CG) and Feira de Santana (FS) in the Northeast. Data were collected through interviews with 514 TB patients under treatment in 2007, using the Primary Care Assessment Tool adapted for TB care in Brazil. Indicators were constructed based on the mean response scores (Likert scale) and compared among the study sites.

Results: "Access to treatment" was evaluated as satisfactory in the Southeast and regular in the Northeast, which displayed poor results on 'home visits' and 'distance between treatment site and patient's house'. "Bond" was assessed as satisfactory in all cities, with a slightly better performance in RP and SJRP. "Range of services" was rated as regular, with better performance of southeastern cities. 'Health education', 'DOT' and 'food vouchers' were less offered in the Northeast. "Coordination" was evaluated as satisfactory in all cities. "Family focus" was evaluated as satisfactory in RP and SJRP, and regular in the others. 'Professional asking patient's family about other health problems' was evaluated as unsatisfactory, except in RP.

Conclusions: Two types of obstacles are faced for health service performance in TB treatment in the cities under analysis, mainly in the Northeast. The first is structural and derives from difficulties to access health services and actions. The second is organizational and derives from the way health technologies and services are distributed and integrated. Incentives to improve care organization and management practices, aimed at the integration of primary, secondary and tertiary services, can contribute towards a better performance of health services in TB treatment.
\end{abstract}

Keywords: Primary Healthcare, Tuberculosis, prevention \& control, Health Care, Health Services Accessibility, Health Services Evaluation

\section{Background}

Even in this millennium, tuberculosis (TB) remains the leading killer infectious disease in the world, with 1.7 million deaths in 2009. One third of the world population is infected by Mycobacterium tuberculosis and a

\footnotetext{
* Correspondence: tite@eerp.usp.br

1 Ribeirao Preto College of Nursing, University of São Paulo, Avenida Bandeirantes, 3900 - Campus Universitário - Ribeirão Preto, SP, CEP: 14040902, Brazil

Full list of author information is available at the end of the article
}

great proportion of the population may develop and transmit the disease to the community [1].

Brazil ranks 19th among the 22 countries with the highest incidence levels of tuberculosis (TB) smear-positive cases [1]. The TB incidence rate was 46 cases/100, 000 inhabitants in 2009, considered one of the highest on the American continent. Although the prevalence and mortality the disease provokes have dropped and cure percentages have increased, from $69 \%$ in 2002 to $71 \%$ in 2009 , this rate still remains far below the recommended $85 \%$ [1].

\section{Biomed Central}


Brazil has considerably invested in health system reform, including the development of new primary health care (PHC) organization and delivery models [2]. The country has recommended TB control as a responsibility of this care level $[3,4]$. To achieve service quality, PHC attributes (access, range of services, coordination, bond and family focus) need to be accomplished, so that a good organization of this level contributes to improve care, with a view to positive impacts on population health and health system efficiency [5].

Despite this recommendation, in some contexts, TB treatment remains centralized in TB reference centers (TRC), so that it has not yet resulted in a uniform performance of health care services in TB control, varying between and within regions.

Disease control cannot be achieved through medical advances alone, such as new diagnostic tests and new drugs. It is important to consider the scenarios and complexity of health care services' context, where technologies are actually incorporated and offered to the community. Currently, research is also lacking a detailed analysis of the interaction between available technologies for TB control and the diversity of local health system contexts, considering the resources, political project and the willingness of local health managers and health care workers [6,7].

Research on the evaluation of PHC performance in TB control in Brazil show that the different care models present in the cities aggregate local (political/organizational/human) specificities, entailing heterogeneity in the dynamics of coping with the disease [8-10].

Considering the diversity of health local systems, regional disparities and inequalities in access to health services that characterize the Brazilian reality, it is appropriate to investigate how health care services carry out TB treatment actions. Thus, this study proposed to evaluate the performance of health services in TB treatment in cities from different Brazilian regions.

\section{Methods}

\section{Research Design and Setting}

A cross-sectional study was conducted in five cities from two Brazilian regions ( 3 in the Southeast and 2 in the Northeast). These cities were intentionally selected due to their epidemiological and operational TB status, as the National TB Control Program considers them priority cities for disease control in their regions, including implementation of the Directly Observed Therapy Short-Course (DOTS) strategy for at least five years.

Ribeirão Preto (RP) and São José do Rio Preto (SJRP), in São Paulo State, and Itaboraí (ITA), in Rio de Janeiro State, are the Southeastern study settings. In 2007, TB incidence in those cities was: 29 cases/100, 000 inhabitants (RP); 32.3 cases/100, 000 inhabitants (SJRP) and
56.1 cases/100, 000 inhabitants (ITA). The Northeastern study sites were Campina Grande (CG), in Paraíba State, and Feira de Santana (FS), in Bahia State, which reached a TB incidence rate of 28.6 cases/100, 000 inhabitants and 28.1 cases/100, 000 inhabitants, respectively [11]. In the same year, TB incidence was 40.6/100, 000 inhabitants in the Southeast and 38.8/100, 000 inhabitants in the Northeast.

Regarding PHC organization, in 2007, FHS coverage corresponded to $23 \%$ in RP, $12 \%$ in SJRP and $68.7 \%$ in ITA. In the Northeast, CG obtained $71 \%$ of FHS coverage and FS $60 \%$. The implementation of the FHS has been taking shape in a heterogeneous way in Brazil, with a team composed by a general practitioner, a nurse, a nursing auxiliaries and 5 to 10 Community Health Workers (CHW), who see to a clientele in a given geographical area.

Historically, a great expansion of the FHS has been observed in areas with poor health resources, aiming to enhance access to health services [12]. This fact has led to a higher FHS coverage rate in the Northeast. In the Southeast, traditional models are still prevalent, structured in Basic Health Units (BHU), in which the teams comprise specialist medical practitioners, nurses and nursing auxiliaries.

As for TB care organization, two types of care models are identified at the study sites: TB care centralized at TB Reference Centers - TRC (RP and FS) or partly decentralized at PHC services (ITA, SJRP and CG).

At TRC, specialized teams conduct TB care with a centralized organization, greater availability of health equipments and provision of diagnostic examinations.

PHC refers to the first level of care provided in the health system and comprises the Family Health Strategy Units (FHS) and Basic Health Units (BHU). Generalist teams conduct $\mathrm{TB}$ care in $\mathrm{PHC}$, with lower availability of technologies.

\section{Participants and Sampling}

The study population was composed of TB patients under treatment in 2007. Patients younger than 18 years (due to ethical considerations) and prison population (due to differences in treatment conduction) were excluded.

The sample size required for ANOVA was 98 patients for each city, calculated using Statistica software (using the commands Several means, ANOVA, 1-Way) and considering the parameters: number of cities $=5$; probability of type I error $=0.05$; probability of type II error $=0.10$, variation due to error $=0.2$. Data collection was conducted over three months (July to September 2007) until the minimum sample size was reached.

From July to September 2007, 618 patients were under treatment for TB, 514 of whom met the inclusion 
criteria and agreed to participate in the survey (100 from RP, 108 from SJRP, 100 from ITA, 106 from CG and 100 from FS).

\section{Data Collection Tool}

To address the issues raised, the theoretical framework of PHC dimensions [13] and the Primary Care Assessment Tool (PCAT) [13] were used, validated in Brazil [14] to evaluate PHC organization and performance and adapted for TB care evaluation [15]. A pilot study was carried out previously.

The instrument to evaluate health service performance in TB control contains questions regarding socio-demographic, clinical and epidemiological aspects, site and type of treatment and specific questions for each organizational PHC component of TB control, divided into five sections:

I - "access to treatment": which involves the location of the health unit near the population it attends, the times and days it is open to treat patients, the degree of tolerance for unscheduled consultations and how the population perceives the convenience of these access aspects [13].

II - "bond" (longitudinality): which implies the existence of a regular source of care and its use over time and requires the establishment of interpersonal bonds that reflect the mutual cooperation between community people and health professionals [13].

III - "range of services" (comprehensiveness): this represents arrangements for the patient to receive any kind of healthcare services required [13].

IV - "coordination": this implies some form of continuity, either care by the same professional, through medical records or both, as well as the recognition of past and new problems. This also includes referral and follow-up care at other specialized services [13].

V - "family focus": which considers the context and family dynamics in care [13].

Interviews with TB patients were conducted to complete the instrument. Patients were interviewed as soon as they went to the health services to perform the medical consultation or DOT, or during home visits. Interviewees should answer each question according to a variety of response scales, such as dichotomous, multiple choice with single answers and a five-point Likert scale, with higher scores for positive responses.

\section{Analysis}

For data analysis, frequency distribution was used to describe the patients' socio-demographical and clinical profile. To analyze the study dimensions, indicators were constructed based on the variables (questions) created for each. The indicators corresponded to the mean value obtained by adding up all responses of all interviewees to each question, divided by the total number of interviewees. Subsequently, an overall indicator was specified for a general analysis of the dimensions, using the mean of responses to all questions pertaining to each study dimension. To test the hypothesis about the existence or lack of similarity between the overall indicators for different cities and regions, analysis of variance (ANOVA), Tukey's test and Student's t-test were performed. The criterion of homoscedasticity was verified using Bartlett's test. The performance of the indicators and dimensions was classified according to the values obtained. Values between 1 and 2 were considered unsatisfactory performance, close to 3 , regular and between 4 and 5 , satisfactory.

\section{Ethical aspects}

Approval for the project was obtained from the Institutional Review Board at the Ribeirão Preto College of Nursing, University of São Paulo (EERP/USP).

\section{Results}

The results showed a higher percentage of male patients (65.6\%), patients with less than 8 years of education (51.1\%) and those with: home ownership (67.9\%), electricity (98.8\%), public water supply at home (86.7\%) and telephone $(70.2 \%)$. The percentage was lower for patients with a private car (26.9\%).

In total, $103(20.0 \%)$ patients received treatment at PHC services and $411(80.0 \%)$ at TRC. Of 514 patients interviewed, 271 (52.3\%) carried out DOT, with $73.8 \%$ at $\mathrm{PHC}$ and $47.5 \%$ at TRC.

The results regarding the types of services that perform TB treatment and DOT coverage are presented per city:

- RP carried out treatment at TRC, 100 (100.0\%); with DOT coverage, 81 (81.0\%);

- SJRP performed treatment at TRC, 81 (75.0\%), and PHC, 27 (25.0\%); with 90 (83.3\%) of DOT coverage;

- ITA performed treatment at PHC, 44 (44.0\%), and TRC, 56 (56.0\%); with 81 (81.0\%) of DOT coverage; - CG performed treatment at PHC, 32 (30.2\%), and TRC, 74 (69.8\%); with 17 (16.0\%) of DOT coverage;

- FS performed treatment at TRC, 100 (100.0\%), and did not carry out DOT.

The overall indicators calculated for the dimensions "access to treatment", "bond", "range of services", "coordination" and "family focus" are presented in tables 1, 2, 3,4 and 5, respectively. Southeastern cities displayed better performance in all dimensions.

The dimension "access to treatment" was evaluated as satisfactory in the three Southeastern cities (RP, SJRP and ITA) and regular in the two Northeastern 
Table 1 Distribution of means and standard deviations of treatment access indicators, Brazilian municipalities, 2007

\begin{tabular}{|c|c|c|c|c|c|}
\hline \multirow[t]{3}{*}{ Indicators of Treatment access } & \multicolumn{3}{|c|}{ Southeastern cities } & \multicolumn{2}{|c|}{ Northeastern cities } \\
\hline & $\mathrm{RP}$ & SJRP & ITA & FS & CG \\
\hline & Mean \pm SD & Mean \pm SD & Mean \pm SD & Mean \pm SD & Mean \pm SD \\
\hline Can you obtain a medical consultation within 24 hours? & $4.59 \pm 1.27$ & $4.47 \pm 1.21$ & $4.21 \pm 1.42$ & $4.34 \pm 1.23$ & $4.01 \pm 1.33$ \\
\hline Do you lose a day of work due to the consultation? & $3.51 \pm 1.82$ & $3.22 \pm 1.79$ & $3.84 \pm 1.72$ & $2.89 \pm 1.94$ & $2.75 \pm 1.71$ \\
\hline Do you use any type of motorized transport to go to the consultation? & $1.93 \pm 1.65$ & $1.66 \pm 1.42$ & $2.21 \pm 1.78$ & $1.71 \pm 1.49$ & $2.33 \pm 1.83$ \\
\hline Do you pay for transport to go to the consultation? & $3.33 \pm 1.92$ & $2.73 \pm 1.86$ & $2.40 \pm 1.86$ & $2.44 \pm 1.82$ & $2.62 \pm 1.81$ \\
\hline During your treatment, has TB medication been lacking? & $4.82 \pm 0.63$ & $4.93 \pm 0.30$ & $4.84 \pm 0.71$ & $4.93 \pm 0.43$ & $4.89 \pm 0.40$ \\
\hline Have you waited more than 60 minutes to be seen for the consultation? & $4.14 \pm 1.30$ & $4.45 \pm 0.85$ & $4.08 \pm 1.40$ & $3.98 \pm 1.44$ & $3.08 \pm 1.32$ \\
\hline Does the health professional often visit you at your home? & $3.85 \pm 1.43$ & $2.94 \pm 1.60$ & $2.52 \pm 1.81$ & $1.80 \pm 1.28$ & $1.59 \pm 1.23$ \\
\hline Do you do the treatment at the HU closest to your house? & $2.77 \pm 1.99$ & $2.90 \pm 1.70$ & $4.16 \pm 1.61$ & $1.44 \pm 1.20$ & $2.13 \pm 1.72$ \\
\hline Total Indicator of Treatment access & $3.64 \pm 1.77^{a}$ & $3.41 \pm 1.76^{a}$ & $3.53 \pm 1.83^{a}$ & $2.94 \pm 1.88^{b}$ & $2.93 \pm 1.79^{b}$ \\
\hline Treatment access by region & & $3.53 \pm 1.79^{*}$ & & 2.93 & $1.83^{*}$ \\
\hline
\end{tabular}

RP - Ribeirão Preto; FS - Feira de Santana; CG - Campina Grande; SJRP - São José do Rio Preto; ITA - Itaboraí.

Note: No statistical differences were found among averages followed by the same letter in columns according to the Tukey test, with significance set at $5 \%$.

*Student t-test $-\mathrm{p}<0.05$

municipalities (FS and CG). 'Need for motorized transportation' was unsatisfactory in all cities. 'Expense with transportation' was also a problem in ITA and FS. Northeastern cities (FS and CG) presented poor results in 'domiciliary visits' and 'distance between treatment site and patient's house' (table 1).

The dimension "bond" was assessed as satisfactory in all cities, with a slightly better performance in RP and SJRP. The indicator 'professionals talk about other health problems' was evaluated as regular in FS, CG and ITA (table 2).

The dimension "range of services" was rated as regular, with better performance of Southeastern cities (RP,
SJRP and ITA). The offering of 'home visits for other reasons than TB' and 'patients' support groups' showed an unsatisfactory evaluation in all study sites. In RP, the 'tuberculosis skin test' was also rated as unsatisfactory. ITA, FS and CG have shown problems with 'transport vouchers'. 'Health education', 'DOT' and 'food vouchers' were less offered in the Northeastern cities (table 3).

The dimension "coordination' was evaluated as satisfactory in all cities (table 4).

The dimension "family focus" was evaluated as satisfactory in RP and SJRP, and regular in ITA, FS and CG. 'Professional asking patient's family about other health problems' was evaluated as unsatisfactory, except in RP.

Table 2 Distribution of means and standard deviations of bond indicators, Brazilian municipalities, 2007

\begin{tabular}{|c|c|c|c|c|c|}
\hline \multirow[t]{3}{*}{ Indicators of Bond } & \multicolumn{3}{|c|}{ Southeastern cities } & \multicolumn{2}{|c|}{ Northeastern cities } \\
\hline & $\mathrm{RP}$ & SJRP & ITA & FS & CG \\
\hline & $\underset{\text { SD }}{\operatorname{Mean} \pm}$ & $\underset{\text { SD }}{\operatorname{Mean} \pm}$ & $\underset{\text { SD }}{\operatorname{Mean} \pm}$ & $\underset{\text { SD }}{\operatorname{Mean} \pm}$ & $\begin{array}{l}\text { Mean } \pm \\
\text { SD }\end{array}$ \\
\hline When you go to the consultation, are you treated by the same professional? & $4.98 \pm 0.20$ & $4.83 \pm 0.48$ & $4.73 \pm 0.62$ & $4.58 \pm 0.83$ & $4.94 \pm 0.30$ \\
\hline $\begin{array}{l}\text { If you have any doubt are you able to speak with the same professional that } \\
\text { treated you? }\end{array}$ & $4.95 \pm 0.36$ & $4.93 \pm 0.35$ & $4.75 \pm 0.80$ & $4.62 \pm 1.02$ & $4.64 \pm 0.81$ \\
\hline Does the professional understand your questions? & $4.91 \pm 0.47$ & $4.88 \pm 0.52$ & $4.81 \pm 0.68$ & $4.84 \pm 0.51$ & $4.74 \pm 0.72$ \\
\hline Does the professional talk with you about other health problems? & $4.09 \pm 1.50$ & $4.43 \pm 1.28$ & $2.71 \pm 1.81$ & $2.93 \pm 1.70$ & $3.20 \pm 1.60$ \\
\hline Does the professional allow sufficient time for you to talk about your doubts? & $4.83 \pm 0.70$ & $4.87 \pm 0.53$ & $4.74 \pm 0.88$ & $4.51 \pm 1.09$ & $4.36 \pm 1.17$ \\
\hline Does the professional respond to your questions in a clear way? & $4.92 \pm 0.42$ & $4.86 \pm 0.59$ & $4.85 \pm 0.63$ & $4.84 \pm 0.58$ & $4.71 \pm 0.73$ \\
\hline Does the professional note your complaints in the medical records? & $5.00 \pm 0.00$ & $4.96 \pm 0.38$ & $4.74 \pm 0.81$ & $4.72 \pm 0.93$ & $4.91 \pm 0.53$ \\
\hline Does the professional explain about the medications used in the treatment of TB? & $4.76 \pm 0.83$ & $4.90 \pm 0.51$ & $4.77 \pm 0.80$ & $4.86 \pm 0.64$ & $4.78 \pm 0.62$ \\
\hline Does the professional ask about all the medications that you are using? & $4.41 \pm 1.36$ & $4.69 \pm 1.02$ & $3.59 \pm 1.84$ & $4.15 \pm 1.51$ & $3.59 \pm 1.61$ \\
\hline What is your opinion about the health team that treats you? & $4.70 \pm 0.52$ & $4.61 \pm 0.59$ & $4.42 \pm 0.62$ & $4.45 \pm 0.66$ & $4.20 \pm 0.81$ \\
\hline Total Indicator of Bond & $\begin{array}{l}4.75 \pm \\
0.83^{\mathrm{a}}\end{array}$ & $\begin{array}{l}4.80 \pm \\
0.70^{\mathrm{a}}\end{array}$ & $\begin{array}{c}4.41 \pm \\
1.24^{\mathrm{b}}\end{array}$ & $\begin{array}{l}4.45 \pm \\
1.15^{\mathrm{b}}\end{array}$ & $\begin{array}{l}4.41 \pm \\
1.12^{\mathrm{b}}\end{array}$ \\
\hline Bond by region & & $4.66 \pm 0.96^{*}$ & & $4.43 \pm$ & $=1.14^{*}$ \\
\hline
\end{tabular}

RP - Ribeirão Preto; FS - Feira de Santana; CG - Campina Grande; SJRP - São José do Rio Preto; ITA - Itaboraí.

No statistical differences were found among averages followed by the same letter in columns according to the Tukey test, with significance set at $5 \%$.

*Student t-test $-\mathrm{p}<0.05$ 
Table 3 Distribution of means and standard deviations of range of services indicators, Brazilian municipalities, 2007

\begin{tabular}{|c|c|c|c|c|c|}
\hline \multirow[t]{3}{*}{ Indicators of Range of services } & \multicolumn{3}{|c|}{ Southeastern cities } & \multicolumn{2}{|c|}{ Northeastern cities } \\
\hline & RP & SJRP & ITA & FS & CG \\
\hline & Mean \pm SD & Mean \pm SD & Mean \pm SD & Mean \pm SD & Mean \pm SD \\
\hline Sputum examination pot for the diagnosis of TB & $4.42 \pm 1.35$ & $4.64 \pm 1.07$ & $4.94 \pm 0.37$ & $4.51 \pm 1.24$ & $4.29 \pm 1.39$ \\
\hline Skin test & $2.07 \pm 1.65$ & $2.82 \pm 1.93$ & $3.12 \pm 1.95$ & $3.09 \pm 1.93$ & $3.08 \pm 1.79$ \\
\hline Examination for HIV/AIDS & $4.30 \pm 1.47$ & $4.44 \pm 1.35$ & $4.38 \pm 1.39$ & $2.87 \pm 1.96$ & $3.00 \pm 1.78$ \\
\hline Monthly sputum examination pot for TB control & $3.93 \pm 1.53$ & $4.03 \pm 1.56$ & $4.76 \pm 0.78$ & $4.21 \pm 1.50$ & $3.86 \pm 1.63$ \\
\hline Monthly consultation for TB control and treatment & $4.93 \pm 0.41$ & $4.88 \pm 0.62$ & $4.93 \pm 0.50$ & $4.66 \pm 1.06$ & $4.80 \pm 0.76$ \\
\hline Consumer basket or food vouchers & $4.15 \pm 1.62$ & $3.89 \pm 1.64$ & $4.47 \pm 1.08$ & $2.65 \pm 1.94$ & $1.06 \pm 0.30$ \\
\hline Transport vouchers & $2.51 \pm 1.90$ & $2.71 \pm 1.88$ & $1.49 \pm 1.28$ & $2.04 \pm 1.67$ & $1.73 \pm 1.33$ \\
\hline Information about TB and its treatment & $4.57 \pm 1.10$ & $4.86 \pm 0.62$ & $4.51 \pm 1.19$ & $4.42 \pm 1.22$ & $3.58 \pm 1.53$ \\
\hline Health education (information about other health issues) & $3.40 \pm 1.86$ & $2.67 \pm 1.69$ & $2.75 \pm 1.88$ & $1.88 \pm 1.39$ & $1.38 \pm 1.02$ \\
\hline Home visits during treatment & $3.72 \pm 1.47$ & $2.94 \pm 1.68$ & $3.21 \pm 1.85$ & $2.50 \pm 1.76$ & $2.01 \pm 1.66$ \\
\hline Home visits for other reasons than TB & $1.16 \pm 0.63$ & $1.16 \pm 0.61$ & $1.99 \pm 1.67$ & $2.25 \pm 1.68$ & $1.71 \pm 1.46$ \\
\hline Participation in TB patient groups at the $\mathrm{HU}$ & $1.05 \pm 0.41$ & $1.05 \pm 0.29$ & $1.36 \pm 1.11$ & $1.12 \pm 0.69$ & $1.04 \pm 0.39$ \\
\hline Directly observed therapy & $3.55 \pm 1.52$ & $3.83 \pm 1.40$ & $3.02 \pm 1.45$ & $1.08 \pm 0.56$ & $1.41 \pm 1.06$ \\
\hline Total Indicator of Range of services & $3.37 \pm 1.85^{\mathrm{a}}$ & $3.38 \pm 1.84^{a}$ & $3.46 \pm 1.84^{a}$ & $2.87 \pm 1.91^{b}$ & $2.53 \pm 1.82^{c}$ \\
\hline Range of services by region & & $3.40 \pm 1.84^{*}$ & & & $1.87^{*}$ \\
\hline
\end{tabular}

RP - Ribeirão Preto; FS - Feira de Santana; CG - Campina Grande; SJRP - São José do Rio Preto; ITA - Itaboraí.

No statistical differences were found among averages followed by the same letter in columns according to the Tukey test, with significance set at $5 \%$.

*Student t-test $-\mathrm{p}<0.05$

In ITA, professionals almost never 'ask patients about their life conditions'. In CG, the 'delivery of sputum pot at patients' home' and 'orientation about TB by professionals to patients' family' were also evaluated as unsatisfactory (table 5).

\section{Discussion}

The results regarding the socio-demographic profile of the TB patients interviewed seem to be similar to those found in most national and international scientific literature, reinforcing the relationship between the disease and social vulnerability [16], demonstrating that the disease mostly affects males and individuals with intermediate education levels [17-19].
The organization of TB patient care in the study cities presented heterogeneity, with treatment coexisting at two types of health services, predominantly medical consultations for treatment at TRC. Some authors reveal that regional disparities and social inequality are strong elements that corroborate the diversity in care delivery in the Brazilian scenario $[4,20]$.

The expansion of the FHS by itself does not guarantee the sustainability of TB control actions in PHC, but a political commitment of managers is necessary [21], through an integrated approach in the health system, which requires permanent and sustained PHC actions [22]. High coverage of FHS did not influence cities' performance in TB care.

Table 4 Distribution of means and standard deviations of coordination indicators, Brazilian municipalities, 2007

\begin{tabular}{|c|c|c|c|c|c|}
\hline \multirow[t]{3}{*}{ Indicators of Coordination } & \multicolumn{3}{|c|}{ Southeastern cities } & \multicolumn{2}{|c|}{ Northeastern cities } \\
\hline & $\mathrm{RP}$ & SJRP & ITA & FS & CG \\
\hline & $\begin{array}{l}\text { Mean } \pm \\
\text { SD }\end{array}$ & Mean \pm SD & Mean \pm SD & $\underset{\text { SD }}{\text { Mean } \pm}$ & $\begin{array}{l}\text { Mean } \pm \\
\text { SD }\end{array}$ \\
\hline $\begin{array}{l}\text { Does the professional from the HU get your medical records during the } \\
\text { consultation? }\end{array}$ & $4.97 \pm 0.30$ & $4.89 \pm 0.50$ & $4.88 \pm 0.61$ & $4.97 \pm 0.22$ & $4.85 \pm 0.70$ \\
\hline When you need the results of your examinations are they available at the HU? & $4.87 \pm 0.69$ & $4.73 \pm 1.82$ & $4.88 \pm 0.50$ & $4.42 \pm 1.26$ & $4.55 \pm 1.00$ \\
\hline Are you advised about scheduling your follow-up appointment at the HU? & $4.96 \pm 0.40$ & $4.93 \pm 0.49$ & $4.86 \pm 0.72$ & $4.92 \pm 0.56$ & $4.84 \pm 0.66$ \\
\hline Total Indicator of Coordination & $\begin{array}{c}4.93 \pm \\
0.49^{\mathrm{a}}\end{array}$ & $\begin{array}{l}4.85 \pm \\
0.62^{ \pm \mathrm{ab}}\end{array}$ & $\begin{array}{l}4.87 \pm \\
0.61^{ \pm \mathrm{b}}\end{array}$ & $\begin{array}{c}4.77 \pm \\
0.84^{\mathrm{b}}\end{array}$ & $\begin{array}{c}4.75 \pm \\
0.81^{\mathrm{b}}\end{array}$ \\
\hline Coordination by region & \multicolumn{3}{|c|}{$4.88 \pm 0.58^{*}$} & \multicolumn{2}{|c|}{$4.76 \pm 0.83^{*}$} \\
\hline
\end{tabular}

RP - Ribeirão Preto; FS - Feira de Santana; CG - Campina Grande; SJRP - São José do Rio Preto; ITA - Itaboraí.

No statistical differences were found among averages followed by the same letter in columns according to the Tukey test, with significance set at $5 \%$.

*Student t-test $-\mathrm{p}<0.05$ 
Table 5 Distribution of means and standard deviations of family focus indicators, Brazilian municipalities, 2007

\begin{tabular}{|c|c|c|c|c|c|}
\hline \multirow[t]{3}{*}{ Indicators of Family focus } & \multicolumn{3}{|c|}{ Southeastern cities } & \multicolumn{2}{|c|}{ Northeastern cities } \\
\hline & $\mathrm{RP}$ & SJRP & ITA & FS & CG \\
\hline & Mean \pm SD & Mean \pm SD & Mean \pm SD & Mean \pm SD & Mean \pm SD \\
\hline $\begin{array}{l}\text { Does the professional ask for information about your living conditions and } \\
\text { those of your family? }\end{array}$ & $3.31 \pm 1.87$ & $4.02 \pm 1.54$ & $2.30 \pm 1.72$ & $2.76 \pm 1.75$ & $2.74 \pm 1.54$ \\
\hline Does the professional ask for information about your family's diseases? & $4.03 \pm 1.62$ & $4.17 \pm 1.36$ & $2.80 \pm 1.83$ & $3.24 \pm 1.75$ & $3.45 \pm 1.40$ \\
\hline Does the professional ask if the people you live with have coughs, fever? & $4.39 \pm 1.36$ & $4.23 \pm 1.38$ & $4.01 \pm 1.58$ & $3.88 \pm 1.62$ & $3.80 \pm 1.42$ \\
\hline $\begin{array}{l}\text { When you became ill with TB did the professional deliver sputum examination } \\
\text { pots to everyone that lives with you? }\end{array}$ & $2.91 \pm 1.98$ & $3.81 \pm 1.67$ & $3.69 \pm 1.89$ & $2.89 \pm 1.92$ & $2.22 \pm 1.55$ \\
\hline Does the professional know the people that live with you? & $4.04 \pm 1.61$ & $3.64 \pm 1.60$ & $4.11 \pm 1.67$ & $3.09 \pm 1.68$ & $2.76 \pm 1.72$ \\
\hline $\begin{array}{l}\text { Do the professionals speak to the people that live with you about your } \\
\text { disease? }\end{array}$ & $3.75 \pm 1.73$ & $3.48 \pm 1.65$ & $3.09 \pm 1.91$ & $2.82 \pm 1.70$ & $2.54 \pm 1.63$ \\
\hline $\begin{array}{l}\text { Do the professionals speak to the people that live with you about your } \\
\text { treatment? }\end{array}$ & $3.72 \pm 1.80$ & $3.50 \pm 1.67$ & $3.05 \pm 1.87$ & $2.84 \pm 1.77$ & $2.46 \pm 1.59$ \\
\hline $\begin{array}{l}\text { Do the professionals speak to the people that live with you about other health } \\
\text { problems? }\end{array}$ & $3.05 \pm 1.90$ & $2.11 \pm 1.55$ & $2.00 \pm 1.65$ & $1.73 \pm 1.41$ & $1.92 \pm 1.46$ \\
\hline Total Indicator of Family focus & $3.65 \pm 1.80^{\mathrm{a}}$ & $3.62 \pm 1.68^{\mathrm{a}}$ & $3.13 \pm 1.90^{\mathrm{b}}$ & $2.91 \pm 1.79^{\mathrm{bc}}$ & $2.74 \pm 1.64^{c}$ \\
\hline Family focus by region & & $3.47 \pm 1.81^{*}$ & & $2.82 \pm$ & $1.72^{*}$ \\
\hline
\end{tabular}

RP - Ribeirão Preto; FS - Feira de Santana; CG - Campina Grande; SJRP - São José do Rio Preto; ITA - Itaboraí.

No statistical differences were found among averages followed by the same letter in columns according to the Tukey test, with significance set at $5 \%$.

*Student t-test $-\mathrm{p}<0.05$

The frequency and site where DOT is performed varied among cities, with greater DOT coverage in cities in the Southeast. Of the five cities, only one (RP) provided DOT at the patients' home. The other cities with higher FHS coverage could present a better performance; however, treatment is conducted at TRC, without establishing partnerships with PHC services, which are provided with Community Health Workers to accomplish this activity. Studies in Brazil have identified that there is a shortage of financial and human resources with appropriate profile to work focused on a community approach and operational difficulties in the use of DOT for most patients under treatment [23].

In this study, predominance of TB treatment at TRC was determinant for poor performance on some "access to treatment" indicators. Such indicators could be addressed through the insertion of TB program actions at PHC services, which are closest to patients' home. Although the medication is free of charge, indirect costs and losses, such as transport and wages lost, respectively, may turn treatment unfeasible and follow-up difficult [24].

To overcome this impasse, some countries propose a health system that combines an outpatient referral unit, a defined team for specialized management at district level, which is responsible for treatment, supervision and monitoring, including PHC participation and responsibility in case search and Directly Observed Therapy (DOT) supervision activities. They also recommend a balance between integration, specificity and decentralization and centralization functions, as well as the inclusion of innovative approaches for specialized groups [25].
All study sites achieved a satisfactory performance on indicators for the dimension "bond". As TRC professionals attend to specific clients in response to a programmed demand, they can dedicate more time to individual case management and understanding of TB patients' singularity. These aspects permit the development of shared responsibilities between patients and health care professionals and the acknowledgement of individual subjectivities involved in the care process [26] and indicate that the "bond" could be more related to the relationship the user establishes with the health service than to the service location in the geographic area.

The dimension "range of services" was evaluated as regular in the five cities, showing that patients face a lack of social support and collective actions. In daily TB treatment situations, even simple cases require the involvement of great care complexity. They demand epidemiological surveillance, clinical actions supported by therapeutic techniques and by integration between individual and collective care, curative and preventive actions, and care and educative activities [27]. Health teams' performance requires more than a clinical approach, and also needs a policy that guarantees the insertion of TB control actions in the health system [28].

The dimension "coordination" was well evaluated in its three indicators and reflects health care professionals' concern related to patient follow-up. For a more detailed analysis of this dimension, other elements are required, such as the analysis of health care service integration, information system quality and reference mechanisms. 
The accomplishment of family-focused actions was evaluated as regular in the cities with high PHC coverage, in contrast with a better evaluation in RP and SJRP. This fact highlights the need to involve family members in the TB patient care process and also include them as an object of care. PHC professionals can accomplish this, have this responsibility and should be included in TB care.

Despite facing the significant implantation and expansion process of the FHS in Brazil, the dominance of the traditional healthcare model is still clear $[29,30]$. In the country, tools to encourage the incorporation of epidemiological surveillance actions in the PHC context "are not always directed to induce a greater integration of the various levels of complexity of care" [31].

The transition from the conventional model of the TRC to the PHC services was identified in some cities, as well as the importance of integrating both. The decentralization of TB control actions to PHC in countries whose health systems have not been consolidated yet demands caution, as it can result in diluted responsibilities, lack of commitment, low quality or lack of laboratory support, fragmentation of treatment regimens and programs, difficulties to accomplish DOT and flaws in information systems capable of providing reliable reports [32].

Therefore, TRC should act as a support for training, supervision, monitoring and evaluating $\mathrm{TB}$ care at the different health system levels. Thus, specific technologies for TB patient treatment and care could be guaranteed, integrating them with other PHC attributes and promoting co-responsibility at all healthcare levels. The struggle for political spaces, ideological and technological aspects [33] remain as obstacles for the achievement of health service integration.

Some limitations and difficulties that were identified in this study are related to the organizational characteristics of the health system and TB care in the cities and to the method (sample size for each city, interviews in violent areas that required the presence of a health care professional, difference in treatment conduction among sites (centralized and decentralized services) and the instrument that needed to be readapted for each treatment organization mode. An operational and epidemiological TB research group enhanced the project development, which works in an integrated way within cities and health services.

\section{Conclusions}

One can affirm that two types of obstacles exist for health service performance in TB treatment in the cities under analysis, mainly in the Northeast. The first is structural and derives from difficulties to access health services and actions. The second is organizational and derives from the way health technologies and services are distributed and integrated. Incentives to improve care organization and management practices, including the integration of primary, secondary and tertiary services, can contribute towards a better performance of health services, and mainly $\mathrm{PHC}$, in TB treatment.

\section{Acknowledgements}

National Council for Scientific and Technological Development (CNPq), process 410547/2006-9; The State of São Paulo Research Support Foundation (FAPESP), process 2008/56479-4; Fogarty International Center/USNIH \# U2RTW006885 ICOHRTA.

\section{Author details}

'Ribeirao Preto College of Nursing, University of São Paulo, Avenida Bandeirantes, 3900 - Campus Universitário - Ribeirão Preto, SP, CEP: 14040902, Brazil. ${ }^{2}$ Departamento de Medicina Social, Ribeirao Preto School of Medicine, University of São Paulo, Ribeirão Preto, SP, Brazil. ${ }^{3}$ Departamento de Medicina Social, Triangulo Mineiro Federal University, Uberaba, MG, Brazil. ${ }^{4}$ Ribeirao Preto College of Nursing, University of São Paulo, Ribeirão Preto, SP, Brazil. ${ }^{5}$ Departamento de Enfermagem Clínica, Paraíba Federal University, João Pessoa, PB, Brazil. ${ }^{6}$ Departamento de Enfermagem em Saúde Pública e Psiquiátrica, Paraíba Federal University, João Pessoa, PB, Brazil. ' State University of Feira de Santana, Feira de Santana, BA, Brazil. ${ }^{8}$ Departamento de saúde Coletiva e Orientação Profissional, São José do Rio Preto School of Medicine, São José do Rio Preto, SP, Brazil.

\section{Authors' contributions}

TCSV coordinated the writing of the manuscript, was the principal investigator, had the concept and design of the study and performed data analysis and discussion; ARN had the concept and design of the study and performed data analysis and discussion; LMS performed data analysis and discussion; RLPA drafted the paper, participated in data collection and performed data analysis and discussion; MEFB and TA participated in data collection and performed data analysis and discussion; JAN, PFP, LDS, MMAS and SHFV participated in data collection and performed data analysis and discussion; AAM and RAA participated in data collection and performed data analysis and discussion. All authors contributed to the interpretation of results, read and approved the final manuscript.

\section{Competing interests}

The authors declare that they have no competing interests.

Received: 23 March 2011 Accepted: 28 September 2011 Published: 28 September 2011

\section{References}

1. World Health Organization: Global tuberculosis control: WHO report Geneva: WHO; 2010.

2. Macinko J, Almeida C, de Sa' P: A rapid assessment methodology for the evaluation of primary care organization and performance in Brazil. Health Policy Plan 2007, 22(3):167-177.

3. Brasil, Ministério da Saúde, Secretaria Executiva: Departamento de Apoio à descentralização. Coordenação Geral de Apoio à gestão Descentralizada. Diretrizes operacionais dos pactos pela vida, em defesa do SUS e de gestão série A - normas e manuais técnicos Brasilia: Ministério da Saúde; 2006 [http://www.saude.caop.mp.pr.gov.br/arquivos/File/volume1.pdf].

4. Giovanella L, Mendonça MHM, Almeida PF, Escorel S, Senna MCM Fausto MCR, Delgado MM, Andrade CLT, Cunha MS, Martins MIC, Teixeira CP: Family health: limits and possibilities for an integral primary care approach to health care in Brazil. Cien Saude Colet 2009, 14(3):783-794.

5. Macinko J, Starfield B, Shi L: The Contribution of Primary Care Systems to Health Outcomes within Organization for Economic Cooperation and Development (OECD) Countries 1970-1998. Health Serv Res 2003, 38(3):831-865 
6. Gandy M, Zumla A: The resurgence of disease: social and historical perspectives on the 'new'tuberculosis. Soc Sci Med 2002, 55(3):385-396, 397-401.

7. Barreto ML, Teixeira MG, Bastos Fl, Ximenes $\mathrm{R}$, Barata $\mathrm{R}$, Rodrigues L: Successes and failures in the control of infectious diseases in Brazil: social and environmental context and research needs. Lancet 2011, 377(9780):1877-1889.

8. Motta MCS, Villa TCS, Golub J, Kritski AL, Ruffino Netto A, Silva DF, Griep RH, Scatena LM: Access to tuberculosis diagnosis in Itaborai City - Rio de Janeiro - Brazil: the patients' point of view. Int J Tuberc Lung Dis 2009, 13(9):1137-1141.

9. Scatena LM, Villa TCS, Rufino-Netto A, Kritski AL, Figueiredo TMRM, Vendramini SHF, Assis MMA, Motta MCS: Difficulties in the accessibility to health services for tuberculosis diagnoses in Brazilian municipalities. Rev Saúde Pública 2009, 43(3):389-397.

10. Figueiredo TMRM, Villa TCS, Scatena LM, Cardozo Gonzales RI, Ruffino Netto A, Nogueira JÁ, Oliveira AR, Almeida AS: Performance of primary healthcare services in tuberculosis control. Rev Saúde Pública 2009, 43(5):825-831.

11. Sistema de Informação de Agravos de Notificação - Information System for Notifiable Diseases. [http://dtr2004.saude.gov.br/sinanweb/index.php? name $=$ Tnet].

12. Bodestein R: Atençao básica na agenda da saúde. Cienc Saude Colet 2002, 7(3):401-412.

13. Starfield B: Atenção primária - equilíbrio entre necessidades de saúde, serviços e tecnologia Brasília: UNESCO, Ministério da Saúde; 2002.

14. Macinko J. Almeida C: Validação de uma metodologia de avaliação rápida das características organizacionais e do desempenho dos serviços de atenção básica do Sistema Único de Saúde (SUS) em nível local Brasília: Organização Pan-Americana da Saúde; 2006

15. Villa TCS, Ruffino-Netto A: Questionário para avaliação de desempenho de serviços de atenção básica no controle da tuberculose no Brasil. J Bras Pneumol 2009, 35(6):610-612.

16. Benatar SR, Upshur R: Tuberculosis and poverty. Int J Tuberc Lung Dis 2010, 14(10):1215-1221.

17. Wahyuni CU, Budiono, Rahariyani LD, Sulistyowati M, Rachmawati T, Yuliwati S, van der Werf MJ: Obstacles for optimal tuberculosis case detection in primary health centers $(\mathrm{PHC})$ in Sidoarjo district, East Java Indonesia. BMC Health Serv Res 2007, 7:135.

18. Rodrigues $L$, Barreto $M$, Kramer M, Barradas BRC: Brazilian response to tuberculosis: challenges and perspectives. Rev Saúde Pública 2007, 41(supl.1):3.

19. Souza JN, Bertolozzi MR: The vulnerability of nursing workers to tuberculosis in a teaching hospital. Rev Latino-Am Enfermagem 2007, 15(2):259-266

20. Escorel S, Giovanela L, Mendonça MHM, Sena MCM: O Programa de Saúde da Família e a construção de um novo modelo atenção básica no Brasil. Rev Panam Salud Publica 2007, 21(2):164-176.

21. Monroe AA, Cardozo Gonzales RI, Palha PF, Sassaki CM, Ruffino Netto A, Vendramini SHF, Villa TCS: Envolvimento de equipes da atenção básica à saúde no controle da tuberculose. Rev EsC Enferm USP 2008, 42(2):262-268.

22. Volmink J, Matchaba P, Garner P: Directly observed therapy and treatment adherence. Lancet 2000, 355(9212):1345-1350.

23. Nogueira JA, Trigueiro DRSG, Sá LD, Silva CA, Ribeiro LCS, Villa TCS, Scatena LM: Enfoque familiar e orientação para a comunidade no controle da tuberculose. Rev Bras Epidemiol 2011, 14(2):207-16.

24. Needham DM, Bowman D, Foster SD, Godfrey-Fausset P: Patient care seeking barriers and tuberculosis programme reform: a qualitative study. Health Policy 2004, 67(1):93-106.

25. Raviglione MC, Pio A: Evolution of WHO policies for tuberculosis control, 1948-2001. Lancet 2002, 359(9308):775-780.

26. Brunello MEF, Cerqueira DF, Pinto IC, Arcêncio RA, Cardozo Gonzales RI, Villa TCS, Scatena LM: Interaction between patient and health care professionals in the management of tuberculosis. Acta Paul Enferm 2009, 22(2):176-182

27. Schraiber LB, Peduzzi M, Sala A, Nemes MIB, Castanhera ERL, Kon R: Planejamento, gestão e avaliação em saúde: identificando problemas. Cien Saude Colet 1999, 4(2):221-242.

28. Ogden J, Walt G, Lush L: The politics of branding in policy transfer: the case of DOTS for tuberculosis control. Social Science \& Medicine 2003, 57(1):179-88.
29. Ibanez N, Rocha JSY, Castro PC, Ribeiro MCSA, Forster AC, Novaes MHD, et al: Avaliação do desempenho da atenção básica no Estado de São Paulo. Cienc Saude Colet 2006, 11(3):683-703.

30. Viana ALD, Rocha JSY, Elias PE, Ibañez N, Bousquat A: Atenção básica e dinâmica urbana nos grandes municípios paulistas, Brasil. Ciênc Saúde Coletiva 2008, 24(Suppl 1):579-90.

31. Almeida C: O SUS que queremos: sistema nacional de saúde ou subsetor publico para pobres? Cien Saude Colet 2003, 8(2):346-69.

32. Frieden $T$, Driver $C$ : Tuberculosis control: past 10 years and future progress. Tuberculosis 2003, 83(1-3):82-5.

33. Mendes EV: As redes de atenção à saúde. Cienc Saude Colet 2010, 15(5):2297-2305

\section{Pre-publication history}

The pre-publication history for this paper can be accessed here: http://www.biomedcentral.com/1472-6963/11/241/prepub

doi:10.1186/1472-6963-11-241

Cite this article as: Villa et al:: Health services performance for TB treatment in Brazil: a cross-sectional study. BMC Health Services Research 2011 11:241.

\section{Submit your next manuscript to BioMed Central and take full advantage of:}

- Convenient online submission

- Thorough peer review

- No space constraints or color figure charges

- Immediate publication on acceptance

- Inclusion in PubMed, CAS, Scopus and Google Scholar

- Research which is freely available for redistribution

Submit your manuscript at www.biomedcentral.com/submit
C Biomed Central 